Article

\title{
Transient Thermal Tensile Behaviour of Novel Pitch-Based Ultra-High Modulus CFRP Tendons
}

\author{
Giovanni Pietro Terrasi ${ }^{1,2, *}$, Emma R. E. McIntyre ${ }^{2}$, Luke A. Bisby ${ }^{2}$, Tobias D. Lämmlein ${ }^{1}$ \\ and Pietro Lura ${ }^{3,4}$ \\ 1 Mechanical Systems Engineering Laboratory, Empa, Swiss Federal Laboratories for Materials Science and \\ Technology, Überlandstrasse 129, CH-8600 Dübendorf, Switzerland; Tobias.Laemmlein@empa.ch \\ 2 BRE Centre for Fire Safety Engineering, Institute for Infrastructure \& Environment, School of Engineering, \\ University of Edinburgh, The King's Buildings Edinburgh, EH93JL Scotland, UK; \\ s0679623@sms.ed.ac.uk (E.R.E.M.); Luke.Bisby@ed.ac.uk (L.A.B.) \\ 3 Concrete and Construction Chemistry Laboratory, Empa, Swiss Federal Laboratories for Materials Science \\ and Technology, Überlandstrasse 129, CH-8600 Dübendorf, Switzerland; pietro.lura@empa.ch \\ 4 Institute for Building Materials (IfB), ETH Zurich, 8092 Zurich, Switzerland \\ * Correspondence: giovanni.terrasi@empa.ch; Tel.: +41-587-654-117; Fax: +41-587-656-911
}

Academic Editors: Alper Ilki and Masoud Motavalli

Received: 24 October 2016; Accepted: 6 December 2016; Published: 21 December 2016

\begin{abstract}
A novel ultra-high modulus carbon fibre reinforced polymer (CFRP) prestressing tendon made from coal tar pitch-based carbon fibres was characterized in terms of high temperature tensile strength (up to $570{ }^{\circ} \mathrm{C}$ ) with a series of transient thermal and steady state temperature tensile tests. Digital image correlation was used to capture the high temperature strain development during thermal and mechanical loading. Complementary thermogravimetric (TGA) and dynamic mechanical thermal (DMTA) experiments were performed on the tendons to elucidate their high temperature thermal and mechanical behaviour. The novel CFRP tendons investigated in the present study showed an ambient temperature design tensile strength of $1400 \mathrm{MPa}$. Their failure temperature at a sustained prestress level of $50 \%$ of the design tensile strength was $409^{\circ} \mathrm{C}$, which is higher than the failure temperature of most fibre reinforced polymer rebars used in civil engineering applications at similar utilisation levels. This high-temperature tensile strength shows that there is potential to use the novel high modulus CFRP tendons in CFRP pretensioned concrete elements for building applications that fulfill the fire resistance criteria typically applied within the construction industry.
\end{abstract}

Keywords: carbon fibre reinforced polymers (CFRPs); high elastic modulus; tensile properties; high temperature behaviour; dynamic mechanical thermal analysis (DMTA); thermogravimetric analysis (TGA)

\section{Introduction}

In the last decade, the precast concrete industry has been progressively developing a range of advanced thin-walled concrete elements utilizing high-performance, self-consolidating concrete reinforced (or prestressed) with high-strength, lightweight, and non-corroding carbon fibre reinforced polymer (CFRP) grids or tendons [1-4]. Due in particular to the stress corrosion resistance of CFRP reinforcements, the concrete cover is not determined by corrosion protection or carbonation issues, as is the case for steel reinforcement and prestressing, and the concrete cover in these bending elements can therefore be reduced to a minimum (e.g., 10-20 mm), leading to lighter and more durable precast elements. The concrete cover size is now determined by static considerations (reception of the compressive stresses due to bending and of the splitting tensile stresses in the prestress transfer zone of prestressing tendons at the beam ends) and by the mismatch in thermal expansion coefficient 
between CFRP (transverse to fibre direction [1]) and high-performance concrete [5]. One example of this trend is a new type of precast CFRP pretensioned concrete element intended as load-bearing panels for glass/concrete building facades [1].

Adequate load carrying capacity during exposure to fire is crucial for applications of CFRP precast concrete structural elements in both the interior and exterior of buildings. Adequate fire resistance is a legitimate concern for these novel precast CFRP reinforced high strength concrete elements, since it is known that the tensile strength of CFRP and the bond strength between CFRP reinforcing tendons and concrete deteriorate comparatively quickly at elevated temperature [6,7]. It is also widely known that high-strength concrete show an increased propensity for heat-induced explosive spalling failure when subjected to fire [8]. The tensile and bond strength decreases experienced in a fire situation, and their impacts on the load-carrying capacity of reinforced and prestressed concrete structures, remain largely unknown particularly for prestressing applications. The spalling behaviour of high-strength concrete can be effectively mitigated by advanced concrete mix design incorporating a suitable quantity and type of polypropylene microfibre [9].

This paper provides insights into the high temperature thermal and tensile strength behavior of novel UHM CFRP tendons that have the potential to effectively reinforce/prestress high-strength concrete elements. The high modulus of the carbon fibers in particular allows considerable load transfer to the fibers in concrete at low strains of the composite (assuming an adequate and durable bond), making these materials suited for reinforcement and prestressing applications in durable, thin-walled concrete precast elements.

A tensile testing machine equipped with a thermal chamber was used to test the novel prestressing tendons under both transient and steady-state high temperature conditions (between 300 and $570{ }^{\circ} \mathrm{C}$ ). Digital image correlation (DIC) enabled the assessment of strains in the CFRP during elevated temperature testing. The aim of these experiments was to characterize the high-temperature tensile response of a specific, novel ultra-high modulus (UHM) pitch-based carbon fibre reinforced polymer (CFRP) tendon and to compare the observed behaviour against that of conventional CFRP prestressing tendons based on polyacrylonitrile (PAN) carbon fibres, as well as to conventional prestressing steel wires. Additional thermo-mechanical analysis (DMTA) and thermogravimetric (TGA) experiments were undertaken to shed further light on the high temperature tensile strength behaviour of the novel reinforcing bars.

\section{Materials Tested}

New pitch-based high modulus carbon fibres with an attractive performance/price ratio are increasingly available for the construction materials market. Examples of such fibres are given in [9], describing industrial-grade fibre rovings composed of 12,000-16,000 single carbon filaments, with an elastic modulus of 640-790 GPa and a tensile strength varying between 2600 and $3200 \mathrm{MPa}$. Their cost is approximately 50 Euro $/ \mathrm{kg}$, which is twice the cost for conventional high strength carbon fibres. Considering that the cost of a carbon fibre reinforced polymer (CFRP) tendon with diameter $5.4 \mathrm{~mm}$ is approximately 4 Euro/m when using conventional high strength carbon fibres, we can estimate the price impact of the new high modulus fibres. If we assume that the novel UHM tendons can be produced by pultrusion, the resulting pultruded tendon price would increase approximately to 4.7 Euro $/ \mathrm{m}$, which is a $17 \%$ increase in price (at a $20 \%-30 \%$ lower tensile capacity). The high tensile strength, corrosion resistance, and low density $\left(2.15 \mathrm{~g} / \mathrm{cm}^{3}\right.$ [10]) of these fibres make them attractive for structural engineering applications. The high modulus of the fibres in particular allows considerable load transfer to the carbon fibres in hybrid material systems at low strains/deformations of the composite (assuming an adequate and durable bond). The drawback of the pitch-based fibres is a comparatively low failure strain for the novel fibres and therefore for tendons manufactured from these fibres; this is between $0.3 \%$ and $0.4 \%$ [10] and must be carefully considered in design of an FRP prestressed structure when using these materials. It is noteworthy that prestressing steel has drastically 
different tensile behaviour, and is typically considered an ideally elastic-plastic reinforcement in design, with a plastic limit strain of between $0.1 \%$ and $0.2 \%$.

The study presented in this paper was focused on a novel type of CFRP tendon, for possible use in civil engineering concrete prestressing applications [11], composed of $66 \%$ by volume Mitsubishi DIALEAD ${ }^{\mathrm{TM}} \mathrm{K} 13916$ fibres [9]. The novel CFRP prestressing tendons have a diameter of $5.3 \mathrm{~mm}$ (with a standard deviation of $\pm 0.1 \mathrm{~mm}$ ) and were produced batch wise by a tape-laying method [12] at a total length of $3.2 \mathrm{~m}$ per tendon. To accomplish this, unidirectional pre-impregnated (prepreg) layers were laid between two pins and then wrapped in the hoop direction with a carbon fibre roving to press them transversely and form a cylindrical geometry. The commercial preimpregnated fibre rovings used had an epoxy polymer matrix (huntsman XB3515/AD5021 [13]), and were hardened for $1.5 \mathrm{~h}$ at $100{ }^{\circ} \mathrm{C}$ followed by $2 \mathrm{~h}$ at $140{ }^{\circ} \mathrm{C}$ before demolding. The tendons' surface was subsequently coated with a lamination epoxy (araldite LY 5052 [13]), and, to promote a strong bond with the surrounding concrete, the tendons were sand coated by broad-casting silica sand (with a mean diameter of $0.5 \mathrm{~mm}$ ). The coating was hardened for two additional hours at $125^{\circ} \mathrm{C}$. The resulting novel UHM CFRP prestressing tendons are shown in Figure 1a.

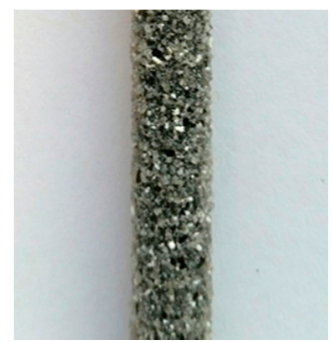

(a)

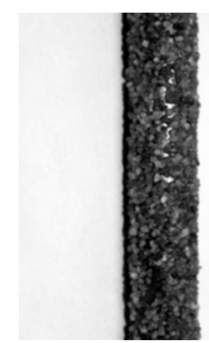

(b)

Figure 1. (a) Novel sand coated ultra-high modulus (UHM) pitch-based carbon fibre reinforced polymer (CFRP) and (b) conventional polyacrylonitrile (PAN)-based CFRP tendon.

These tendons behave linear elastically until tensile failure (Figure 2), have an average tensile strength of $1561 \mathrm{MPa}$ (with a standard deviation of $\pm 68.05 \mathrm{MPa}$ from six tensile tests) and an average $E_{11}$ modulus (measured following [14]) of $509 \mathrm{GPa}$ ( $\left.\pm 13.49 \mathrm{GPa}\right)$. The resulting Design Tensile Strength (DTS) is $1400 \mathrm{MPa}$. The DTS was calculated from the results of the six tensile tests shown in Figure 2 using the average measured strength of $1561 \mathrm{MPa}$ (Table 1), the standard deviation of $68.05 \mathrm{MPa}$ and assuming a normal distribution of the tensile strengths (which is one possible assumption following [15]). The DTS was defined as the average tensile strength minus 2.3 standard deviations, corresponding to the 2.1 percentile.

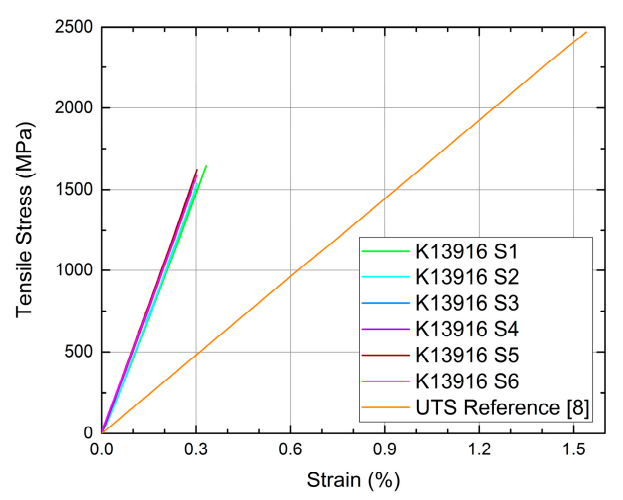

Figure 2. Tensile stress versus strain response of new UHM CFRP tendons (6 specimens labelled K13916 S1 to S6), compared with a conventional CFRP prestressing tendon [8]. 
Table 1. Comparison of the tensile properties of UHM CFRP tendons versus standard CFRP tendons.

\begin{tabular}{|c|c|c|c|c|c|c|}
\hline Material & $\begin{array}{l}\text { Fibre volume } \\
\text { content }(\%)\end{array}$ & $\begin{array}{c}E_{11 \text { calc. }}[14] \\
(\mathrm{GPa})\end{array}$ & $\begin{array}{l}E_{11 \text { exp. }} \\
\text { (GPa) }\end{array}$ & $\begin{array}{l}\sigma_{11 \text { max calc. }} \\
\text { [14] (MPa) }\end{array}$ & $\begin{array}{c}\sigma_{11 \max \text { exp }} \\
(\mathrm{MPa})\end{array}$ & $\begin{array}{c}\sigma_{11 \text { failure exp. }} \\
(\%)\end{array}$ \\
\hline UHM CFRP tendon K13916 & 66 & 502 & 509 & 2112 & 1561 & 0.30 \\
\hline Standard CFRP tendon UTS5631 [1] & 65 & 150 & 156 & 3096 & 2471 & 1.54 \\
\hline
\end{tabular}

Figure 3a shows the brittle failure that was observed during tensile testing of the CFRP tendons at the loaded end of the resin-cast anchorage that was used to grip the tendon during testing. A close-up of the brittle CFRP failure surface at the same location is given in Figure $3 \mathrm{~b}$. This failure mode, and the resulting tensile capacity of the tendons, was clearly influenced by the complex stress state at the loaded end of the resin cast anchorage system [11]. A combination of tensile stress along the tendon axis, a superimposed compression (clamping) stress transverse to the tendon axis, and a peak in shear stress at the entrance of the tendon to the anchorage caused a premature and brittle shearing-off the CFRP at this location. A potential solution to the pronounced strength anisotropy and matrix-bond problem of the UHM fibres [15] would be to design a tensile anchorage system and corresponding test setup which leads to smaller transverse stress peaks. Analysis of bending tests of under-reinforced concrete beams prestressed with these UHM tendons (Empa, unpublished results) showed that when designing for the tensile failure of the CFRP tendon, tensile stresses in the outermost tendon reached levels around $1900 \mathrm{MPa}$ at flexural failure of the beam.

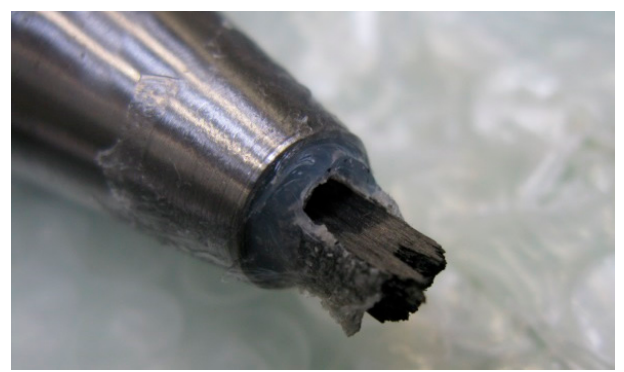

(a)

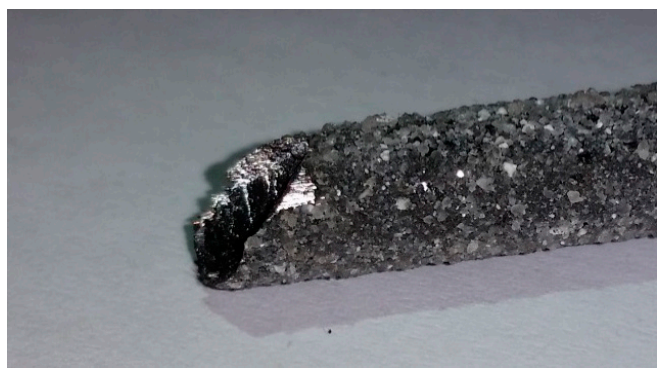

(b)

Figure 3. (a,b) Brittle failures of two UHM CFRP tendons at the load entrance of the resin-cast metallic barrel anchor used to anchor the tendons during the tensile tests.

According to the rule of mixtures for unidirectional fibre reinforced polymers [15], and considering that the Mitsubishi DIALEAD ${ }^{\mathrm{TM}} \mathrm{K} 13916$ carbon fibres have a guaranteed tensile strength of $3200 \mathrm{MPa}$ [10], the theoretical tensile strength of the UHM CFRP tendons is $0.66 \times 3200 \mathrm{MPa}=2112 \mathrm{MPa}$, which is $35 \%$ higher than the average tensile strength measured in the tests described above. This is likely due to the observed premature failure mode next to the anchors (see Table 1). A similar approach shows that the experimentally-determined tensile elastic $\left(E_{11}\right)$ modulus of the novel tendons (509 GPa) is accurately estimated with the rule of mixtures [15], which suggests to $0.66 \times 760 \mathrm{GPa}=502 \mathrm{GPa}$.

The thermomechanical behaviour of the new UHM tendons was compared against conventional CFRP tendons used for concrete pre-tensioning applications $[1,6,11]$. The more conventional CFRP tendons have a nominal diameter of $5.4 \mathrm{~mm}( \pm 0.1 \mathrm{~mm})$ and were produced by pultrusion. PAN based carbon fibres in the conventional tendons were TENAX ${ }^{\mathrm{TM}}$ UTS 5631 [16] at a carbon fibre volume fraction of $65 \%$. These tendons had an epoxy polymer resin matrix consisting of Bakelite Ruetapox VE 4434 resin [17]. A sand coating was also applied to the surface of these bars by in-line spray-coating silica sand onto a coating of epoxy resin (araldite LY 5052 [13]), applied after the primary pultrusion and curing process, as described previously, and resulting in a coating approximately $0.5 \mathrm{~mm}$ thick. The CFRP tendons' average nominal tensile strength was $2471 \mathrm{MPa}$ (standard deviation of $\pm 168 \mathrm{MPa}$ from 45 tensile tests), with an elastic modulus $E_{11}$ [14] of $156 \mathrm{GPa}$. The tensile stress-strain relationship for the reference CFRP tendons was linear-elastic to failure (Figure 2), and displayed an average 
ultimate strain of $1.54 \%$ [1]. Both CFRP tendons studied herein have a nominal mass of $0.123 \mathrm{~kg} / \mathrm{m}$, which is about half the mass per unit length of a standard $6 \mathrm{~mm}$ diameter cold-drawn steel prestressing wire [18], and about $47 \%$ of the mass per unit force. A sample of the reference CFRP prestressing tendon is shown in Figure 1b.

\section{Experimental Programme}

The primary aim of the study presented herein was to experimentally characterize the transient elevated temperature tensile behaviour of the novel pitch-based carbon fibre reinforced epoxy tendons described in the previous section. It was of interest to compare the response of the novel tendons with the behaviour [6] of the conventional normal modulus CFRP prestressing tendons based on Polyacrylonitrile (PAN) carbon fibres. Two sets of high-temperature experiments were performed for the new UHM tendons in a materials testing frame equipped with a high temperature environmental chamber. The experiments consisted of 11 transient elevated temperature tensile tests-In which the CFRP was loaded to a sustained load and then heated under constant load until failure-Followed by two steady state high temperature tensile tests of the new UHM tendons at $300{ }^{\circ} \mathrm{C}$, in which the tendons were heated to a constant temperature and then loaded under constant temperature until failure.

The total length of each tensile specimen was $810 \mathrm{~mm}$, which led to a free testing length of $500 \mathrm{~mm}$ between the $140 \mathrm{~mm}$ long steel barrel anchorages (Figure 4). The crucial issue of gripping the tendons, which is far from straightforward for this type of tendon, was addressed by epoxy bonding high strength steel sockets (Grade ETG 100 [19]) to both tendon ends. After spraying a polytetrafluoroethylene (PTFE) separating layer on the anchorages' inner surfaces, the CFRP tendon specimens were centered and fixed with a silicone drop at the load entrance of the steel anchorages. A low-viscosity lamination epoxy resin (Araldite LY 5052 [13]) was then cast into the conical interior of the cylindrical steel sockets [5]. Half of the steel anchorages were ground to a conical shape at the load entrance (Figures 3a and 4) in order to make this region of the socket softer, which gave better results when performing tensile tests at ambient temperature [5]. An M36 ISO metric screw thread was cut into the external surface of the steel anchorages in order to fix them to steel adaptors that were then clamped into the wedge action grips of the materials testing frame, as shown in the highlighted area of Figure 5a.

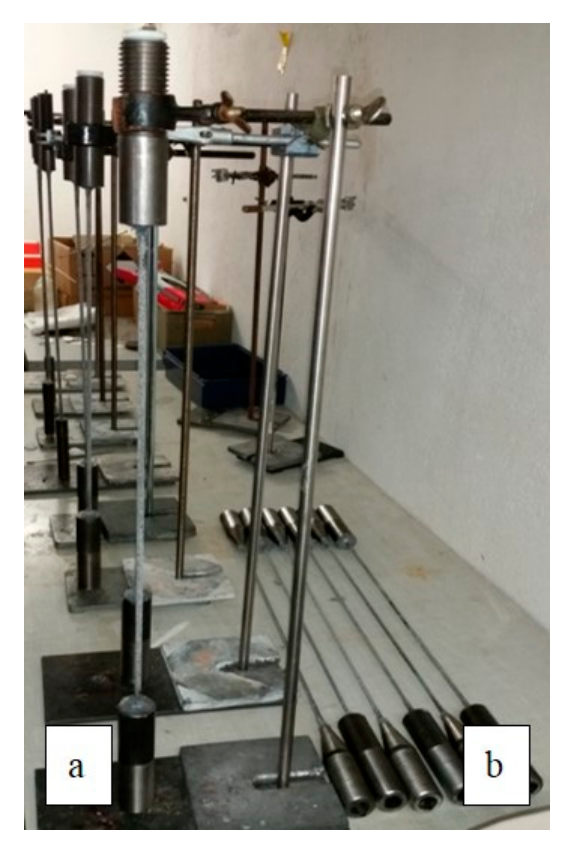

Figure 4. (a) Setup to cast epoxy grout anchorages; (b) Six CFRP specimens with testing anchors installed. 


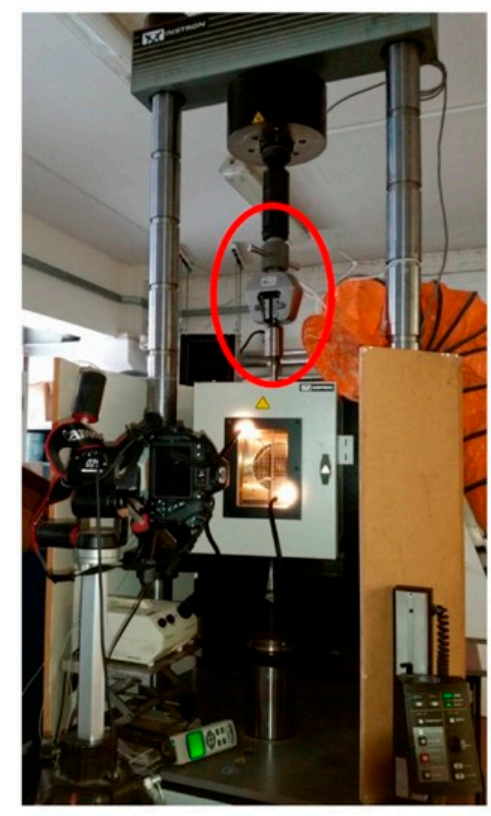

(a)

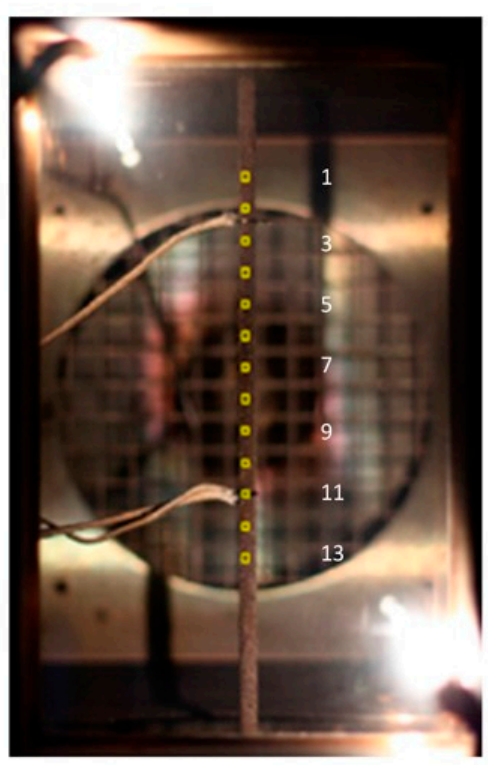

(b)

Figure 5. (a) Test setup with DIC camera in front of Instron 600 LX tensile testing machine equipped with environmental chamber; the upper tendon's anchorage clamping device is highlighted; (b) Detail showing a CFRP specimen with three attached thermocouples and the DIC patch alignment/numbering for strain measurement.

A high-capacity materials testing frame at the University of Edinburgh's BRE Centre for Fire Safety Engineering (Edinburgh, Scotland, UK), which includes an in-line environmental chamber, was used for the tensile tests (Figure 5). The setup consisted of an Instron $600 \mathrm{LX}$ static hydraulic universal testing machine (Instron, Norwood, MA, USA) with a tension/compression load capacity of $600 \mathrm{kN}$, equipped with an Instron CP103790 high temperature environmental chamber (Instron, Norwood, MA, USA) capable of covering a temperature range from -70 to $+620^{\circ} \mathrm{C}$ (temperature stability $\pm 2{ }^{\circ} \mathrm{C}$, heating rate $10^{\circ} \mathrm{C} / \mathrm{min}$ ). The anchorages of the tensile specimens were clamped using spherically seated wedge action grips with $150 \mathrm{kN}$ capacity both above and below the environmental chamber.

The transient thermal tensile tests were performed at a crosshead stroke rate of $0.5 \mathrm{~mm} / \mathrm{min}$ up to the predefined prestress level, and three representative prestress levels were studied; namely $40 \%$, $50 \%$, and $60 \%$ of the tendon's design Ultimate Tensile Strength of $1400 \mathrm{MPa}$. These prestress levels are representative of the long-term in service stresses expected for CFRP tendons in pre-tensioned precast concrete elements [1] in practice. The CFRP tendons were thus stressed to corresponding service stresses of 560,700 , and $840 \mathrm{MPa}$, with three or four specimens tested at each stress level, and then heated at a rate of $10{ }^{\circ} \mathrm{C} / \mathrm{min}$ under a sustained load control mode until failure (or until the maximum stable temperature of $570 \pm 2{ }^{\circ} \mathrm{C}$ of the environmental chamber was reached).

For the two steady state tests, the UHM specimens were prestressed to a small stress of only $100 \mathrm{MPa}$ during heating up to $300^{\circ} \mathrm{C}$, again at a heating rate of $10^{\circ} \mathrm{C} / \mathrm{min}$, and then loaded to failure under a crosshead stroke controlled loading at a rate of $0.5 \mathrm{~mm} / \mathrm{min}$.

One K-type ThermoCouple (TC) (denoted as $\mathrm{TC}_{2}$, Empa, Dübendorf, Switzerland) was positioned in the gas phase at the center of the testing chamber, and was used to control the chamber's temperature. Three additional type $\mathrm{K}$ thermocouples (denoted as $\mathrm{TC}_{1}, \mathrm{TC}_{3}$, and $\mathrm{TC}_{4}$ ) were tied onto the CFRP specimen using $0.3 \mathrm{~mm}$ steel wires: $\mathrm{TC}_{1}$ at $95 \mathrm{~mm}$ and $\mathrm{TC}_{3} / \mathrm{TC}_{4}$ at $190 \mathrm{~mm}$ from the top inner surface of the temperature chamber (see Figure 5). These additional TCs were used to monitor the temperature of the tendon and the uniformity of temperature within the chamber and on the test specimens. 
A digital single lens reflex (DSLR) camera of type Canon 650d (18 Megapixel CMOS, 50mm fixed focal length lens, Canon Inc., Tokyo, Japan) was used for DIC analysis to measure the axial deformations of the tendons during the tensile tests (see Figure 5). The camera was used to acquire high-resolution digital images of the sand-coated surface of the CFRP tendons, at a rate of $0.2 \mathrm{~Hz}$. A custom-coded Matlab module called GeoPIV (Version RG, Queen's University, Kingston, ON, Canada) was used for the DIC analysis; this was developed by Take et al. at Cambridge University, UK, and Queen's University, Canada [20]. The initial DIC analysis was carried out with $32 \times 32$ pixel patches ( $2.3 \mathrm{~mm}$ square in the images based on an average scale factor amongst the tests). Data from this analysis displayed considerable scatter, so an additional DIC analysis was performed using $64 \times 64$ pixel patches, which significantly improved the output. Thirteen patches were used in a vertical formation on each CFRP bar, as shown in Figure $5 \mathrm{~b}$. The initial stress vs. DIC-derived strain behaviour showed an increase in stiffness during the loading phase, before starting the transient tensile thermal experiments. This indicated minor out-of-plane movement of the test specimen in the early stages of loading (i.e., during seating of the specimens). Linear extrapolation, using a tangent determined in the tensile stress range between 300 and $700 \mathrm{MPa}$, was used to correct for this error.

Thermogravimetric analysis (TGA) (A Netzsch TG 209 F1, Netzsch GmbH, Selb, Germany) was performed on the UHM tendon material to characterise its thermal degradation in an unstressed state. Two uncoated samples of the CFRP tendon core material (discs of $3 \mathrm{~mm}$ diameter and approximately $1 \mathrm{~mm}$ height) were cut with a diamond saw from a tendon that had previously had its sand coating mechanically removed. The two samples were cleaned with acetone, had starting weights of $12.2 \mathrm{mg}$, and were conditioned in a storage room at $23{ }^{\circ} \mathrm{C}$ and $50 \%$ Relative Humidity $(\mathrm{RH})$ before performing the TGA tests. A Netzsch TG 209 F1 Iris thermos-microbalance was used, with tests performed in air at a heating rate of $20^{\circ} \mathrm{C} / \mathrm{min}$ over the range from 25 to $900{ }^{\circ} \mathrm{C}$. The testing precision was $\pm 0.01 \mathrm{mg}$.

Dynamic Mechanical Thermal Analysis (DMTA) was also performed on two specimens of the novel UHM tendons, to provide further insights into the thermomechanical response of the novel material and, crucially, to determine its glass transition temperature $\left(T_{g}\right)$ by various possible definitions. A dynamic mechanical thermal analyser EPLEXOR 500 (Gabo Qualimeter GmbH, Ahlden (Aller), Germany), with built-in displacement sensors and a $500 \mathrm{~N}$ load cell, was used. For each $50 \mathrm{~mm}$ long specimen, two DMTA tests were performed in a 3-point bending mode in accordance with [21] (displacement controlled, $40 \mathrm{~mm}$ span). The static base load was chosen to induce a $0.2 \%$ tensile strain at mid-span, over which a dynamic displacement causing $\pm 0.082 \%$ strain amplitude was superimposed at a frequency of $1 \mathrm{~Hz}$. The temperature range was between 20 and $210{ }^{\circ} \mathrm{C}$, at a heating rate of $2{ }^{\circ} \mathrm{C} / \mathrm{min}$. The sand coating was removed from the original tendons at their support locations and the specimens were stored in lab conditions before testing ( 1 month in a $23{ }^{\circ} \mathrm{C} / 50 \% \mathrm{RH}$ climate). The $T_{g}$ values were calculated both using an $E^{\prime}$ (storage modulus) onset definition, and using a peak $\tan \delta$ definition [21].

\section{Results}

Selected results of the transient thermal tensile tests are summarized in Table 2. At $50 \%$ of DTS the average failure temperature of the new UHM tendons was $409^{\circ} \mathrm{C}$ (from four repeat tests with a standard deviation of $\pm 8.3{ }^{\circ} \mathrm{C}$ ), while at $60 \%$ of DTS the average failure temperature decreased to $395{ }^{\circ} \mathrm{C}$ (three tests, $\pm 9{ }^{\circ} \mathrm{C}$ ). The failure temperature in these tests was defined as the average temperature of the measuring thermocouples attached to the tendon, at the moment when loss of prestress occurred; this was initiated by the successive tensile failure of the near-surface fibres (which were at this point 'dry' due to the epoxy matrix having pyrolysed). For the lowest prestress level of $560 \mathrm{MPa}$ (corresponding to $40 \%$ of DTS), failure was not reached during any of the tests. Thus, after holding the load constant for $10 \mathrm{~min}$ at a temperature of $570{ }^{\circ} \mathrm{C}$, it was decided to increase the tensile stress from $560 \mathrm{MPa}$ up to failure (at a crosshead displacement rate of $1 \mathrm{~mm} / \mathrm{min}$ ) to determine the remaining tensile strength at that temperature. The resulting average remaining tensile strength was $644 \mathrm{MPa}( \pm 18 \mathrm{MPa})$; this corresponds to $46 \%$ of DTS. 
Table 2. Results of transient thermal tensile tests of prestressed UHM tendons. n.a. means not applicable.

\begin{tabular}{ccc}
\hline Constant stress (MPa) $(\%$ of DTS) & Mean failure temperature $\left({ }^{\circ} \mathbf{C}\right)($ Stdv) & CFRP strain at failure estimated by DIC (\%) \\
\hline $560(40 \%)$ & No failure at $570{ }^{\circ} \mathrm{C}$ & - \\
$700(50 \%)$ & $409(8.3)$ & $0.18 \%-0.22 \%$ \\
$840(60 \%)$ & $395(9.0)$ & n.a. \\
\hline
\end{tabular}

In the two steady-state tensile tests, the UHM specimens were prestressed to $100 \mathrm{MPa}$ and then heated to $300 \pm 5{ }^{\circ} \mathrm{C}$. A crosshead displacement controlled loading was then applied until failure. The first specimen failed at $1004 \mathrm{MPa}$ (72\% of DTS), whereas the second failed at $1037 \mathrm{MPa}$ (74\% of DTS).

Figure 6 shows typical tensile strain versus temperature curves for one of the specimens loaded at $50 \%$ of DTS (Specimen 50c), with the strains captured using DIC by measuring the increase in spacing between two patches (e.g., '13-1' denotes the average strain measured between patches no. 13 and no. 1 in Figure 5b). It is noteworthy that these data are smoothed based on a LOcal regression (LOESS) model [22]. The longitudinal tendon strain increases linearly during the initial loading phase to reach the predefined prestress level corresponding to the initial horizontal plateau in the data in Figure 6. Thereafter, the temperature is increased at a rate of $10{ }^{\circ} \mathrm{C} / \mathrm{min}$ until failure, and the resulting strains are evident. Given that the fibres in the UHM specimens are carbon, it was expected that there would be a small strain reduction during the heating phase of the experiment (since the bars' coefficient of thermal expansion in the fibre longitudinal direction $\mathrm{CTE}_{11}$ is slightly negative, i.e., $-1.2 \times 10^{-6}$ in the range between 50 and $125^{\circ} \mathrm{C}$ [10]). This expectation is confirmed by the data up to temperatures of approximately $250^{\circ} \mathrm{C}$. Figure 6 clearly shows a turning point in the data in the temperature range between 270 and $320^{\circ} \mathrm{C}$, where the strains begin to increase on further heating. For all specimens prestressed at $50 \%$ of DTS and investigated with DIC during testing, this temperature range was determined to be between 260 and $360^{\circ} \mathrm{C}$ based on the minimum strain value observed after the onset of heating. Based on the TGA data (see Figure 7), this range indicates the onset of matrix thermal decomposition. It is noteworthy that the TC readings during testing are surface temperatures, and do not necessarily represent the tendon core temperature. The specimen failure was signaled by rapidly increasing strains starting at approximately $360^{\circ} \mathrm{C}$, somewhat below the average failure temperatures reported in Table 2. The decomposition of the epoxy from the bars' surface inwards, combined with creep of the epoxy matrix inside the bars, may explain this difference.

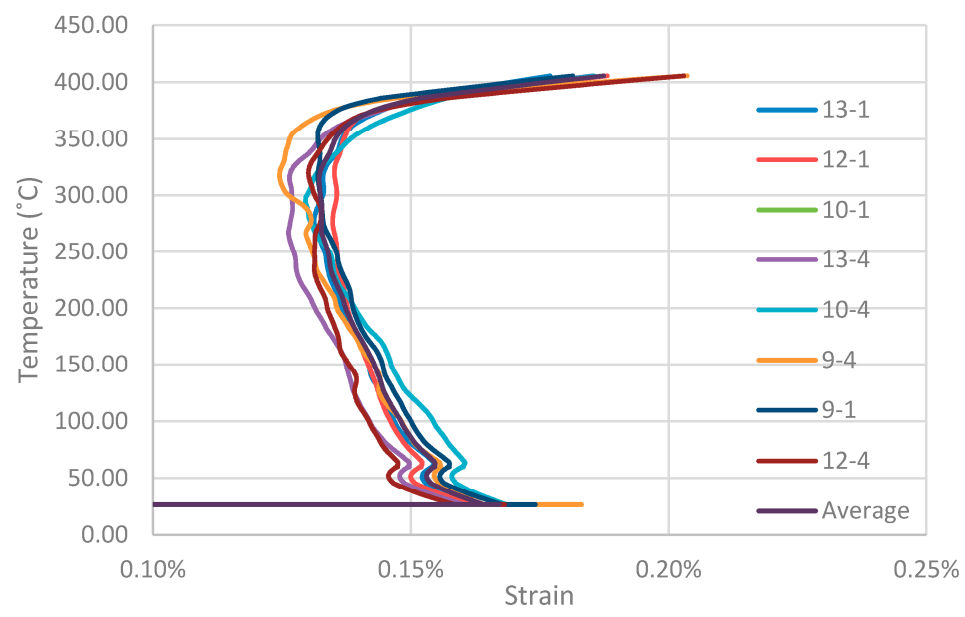

Figure 6. DIC-measured tensile strain versus temperature curves for the transient thermal tests of Specimen 50c subjected to a prestress of $700 \mathrm{MPa}$ (50\% of DTS). 


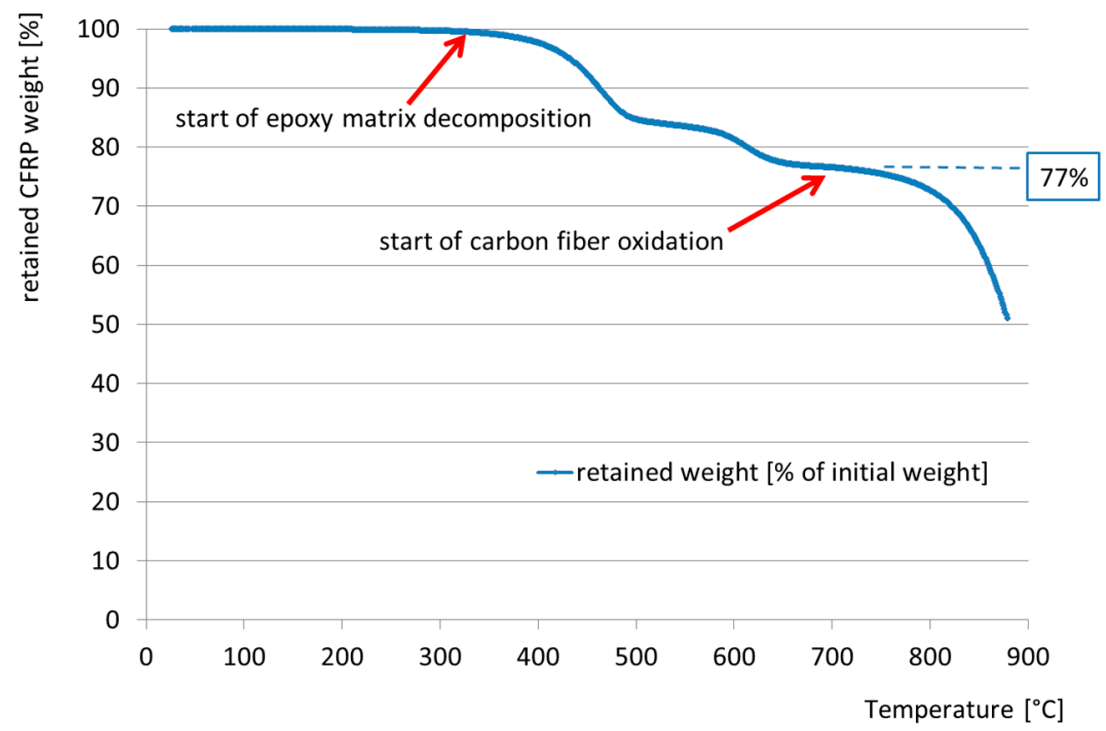

Figure 7. Thermogravimetric (TGA) plot (mass loss vs. temperature) for the UHM CFRP material.

The strain at failure of the tendons $(0.18 \%-0.22 \%$ for a sustained stress of $700 \mathrm{MPa}$, as shown in Table 2) has been reduced based on the expected quasi-static strain at $700 \mathrm{MPa}$ to filter out the bar movement during the loading phase. On this basis, the strain calculations assume that the distance between the camera lens and the foremost surface of the bar is unchanged from the initial calibration carried out at the start of the experiment; therefore it is expected that the results will contain some small calibration errors, and as such should only be considered as an illustrative estimate.

Figure 8 shows one UHM CFRP specimen prestressed at $700 \mathrm{MPa}(50 \%$ of DTS) immediately before and after failure (at $410{ }^{\circ} \mathrm{C}$ in this case). At temperatures above $400{ }^{\circ} \mathrm{C}$, the epoxy matrix is completely decomposed and the 'dry fibres' are carrying the applied loads (albeit with some charred matrix residue remaining). The fibres relax after failure and the cross section physically opens (Figure 8 right). The sudden increase in strain is clearly visible comparing these two images using the auxiliary horizontal blue lines drawn.

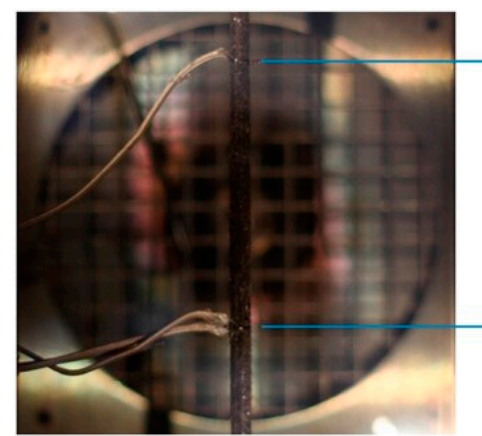

(a)

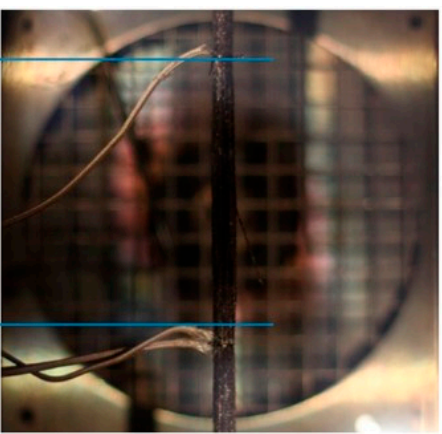

(b)

Figure 8. CFRP specimen prestressed at $700 \mathrm{MPa}$ (Specimen 50d) immediately before (a) and after failure (b).

The relative retained mass versus temperature measured for the novel UHM-CFRP in the TGA is given in Figure 7. The thermal degradation of the epoxy resin (which makes up 23\% of its initial mass) starts at approximately $300{ }^{\circ} \mathrm{C}$ and ends at approximately $680^{\circ} \mathrm{C}$. The authors hypothesize that the first mass drop represents the pyrolysis of the epoxy matrix, and the second (starting at approximately $570{ }^{\circ} \mathrm{C}$ ) is caused by char/residue oxidation, while the oxidation of the carbon fibres themselves 
(the remaining $77 \%$ of the mass of the tendon) follows from about $680{ }^{\circ} \mathrm{C}$ [23], and continues until $900{ }^{\circ} \mathrm{C}$ (the end of the TGA test).

The DMTA experiments of two specimens of the novel UHM tendons gave more insight into their thermo-mechanical response (Figure 9). The storage modulus $E^{\prime}$ (primary axis) versus temperature is depicted next to the tangent of the phase shift angle $\delta$ (on the secondary axis) versus temperature. The two specimens were measured in two consecutive DMTA heating runs between 20 and $210{ }^{\circ} \mathrm{C}$. The results of the second heating run produced essentially the same $E^{\prime}$ versus temperature and $\tan \delta \mathrm{vs}$. temperature curves as in the first run, and are not reproduced in Figure 9.

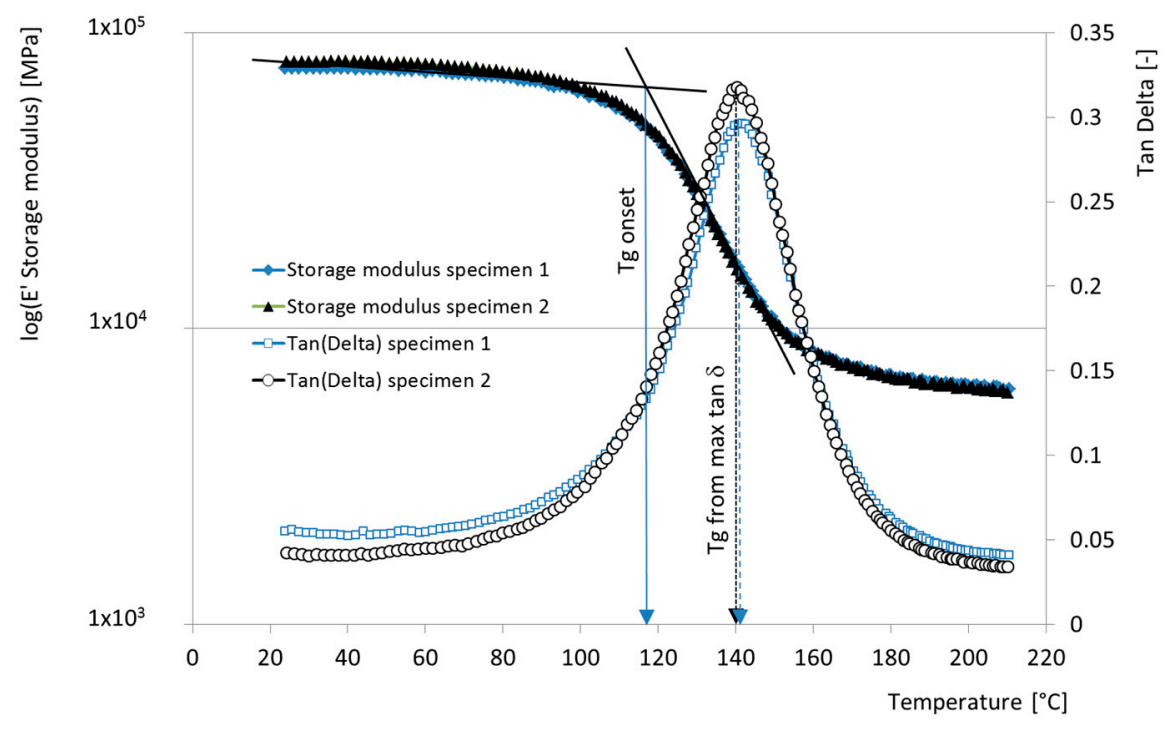

Figure 9. Results of DTMA analysis, $E^{\prime}$ and $\tan \delta$ versus temperature for the novel UHM CFRP tendons.

Table 3 summarizes the $T_{g}$ values determined following a 'Peak $\tan \delta^{\prime}$ definition [21] and a more conservative ' $T_{g}$ onset' definition (used in [6]). As already noted, each sample was retested with the same DMTA protocol to observe whether an increase in $T_{g}$ would take place. This would be a clear sign of a post-hardening of the epoxy matrix of the tendon during the first heating cycle. No such shift in $T_{g}$ was observed, and the $T_{g}$ values measured for the second DMTA run were between $0.9^{\circ} \mathrm{C}$ and $2.3{ }^{\circ} \mathrm{C}$ lower than in the first measurement run (see Table 3); this is within the uncertainty of the instrumentation used $\left( \pm 3^{\circ} \mathrm{C}\right)$. The DMTA results for the novel UHM tendons are similar to those obtained in [1,5] for the conventional CFRP tendons (properties in Table 1 and further elaborated in [1]). The average $T_{g}$ onset for the conventional tendons was observed to be $121^{\circ} \mathrm{C}[6]$, and the average $T_{g}$ (peak $\tan \delta$ ) was $135^{\circ} \mathrm{C}[1]$.

Table 3. $T_{g}$ values for UHM CFRP tendons measured during first and second heating runs of DMTA testing.

\begin{tabular}{ccc}
\hline Sample/Run & $T_{g}$ (onset $\left.\mathrm{E}^{\prime}\right)\left({ }^{\circ} \mathrm{C}\right)$ & $T_{g}(\max \tan \delta)\left({ }^{\circ} \mathrm{C}\right)$ \\
\hline $\mathbf{1 / 1}$ & $116 \pm 1$ & $142 \pm 1$ \\
$\mathbf{1 / 2}$ & $115 \pm 1$ & $139 \pm 1$ \\
$\mathbf{2} \mathbf{1}$ & $117 \pm 1$ & $140 \pm 1$ \\
$\mathbf{2 / 2}$ & $115 \pm 1$ & $139 \pm 1$ \\
\hline
\end{tabular}

\section{Discussion}

The high-temperature tensile strength results of the novel UHM CFRP tendons (Table 2) are considered to be comparatively good when compared to the high temperature performance of typical FRP reinforcements for concrete structures. A literature review in [7] concluded that, at temperatures between 250 and $400{ }^{\circ} \mathrm{C}$, most carbon/epoxy CFRP composites lose about half of their original tensile 
strength. The novel UHM CFRP tendons investigated in the present study have a design tensile strength of $1400 \mathrm{MPa}$, and their failure temperature at a prestress of $50 \%$ of the design tensile strength was found to be $409^{\circ} \mathrm{C}$ (Table 2), which is at (or above) the upper end of the accepted temperature range for this stress value.

A comparison of the tensile strength of the novel UHM tendons with the thermal behaviour of standard (PAN-based) CFRP tendons [6] versus that obtained from prior tests on deformed high tensile steel prestressing wires of type BS 5896 [24] is shown in Figure 10. The Eurocode 1992-1-2 [25] high-temperature design tensile strength reduction curve for Class A cold drawn prestressing steel wires is also included in Figure 10 for comparison. The secondary axis of Figure 10 also shows the retained mass of the novel CFRP material during thermogravimetric analysis. Highlighted are the start of the epoxy matrix decomposition, at approximately $300^{\circ} \mathrm{C}$, and the start of the carbon fibre oxidation, at around $680^{\circ} \mathrm{C}$.

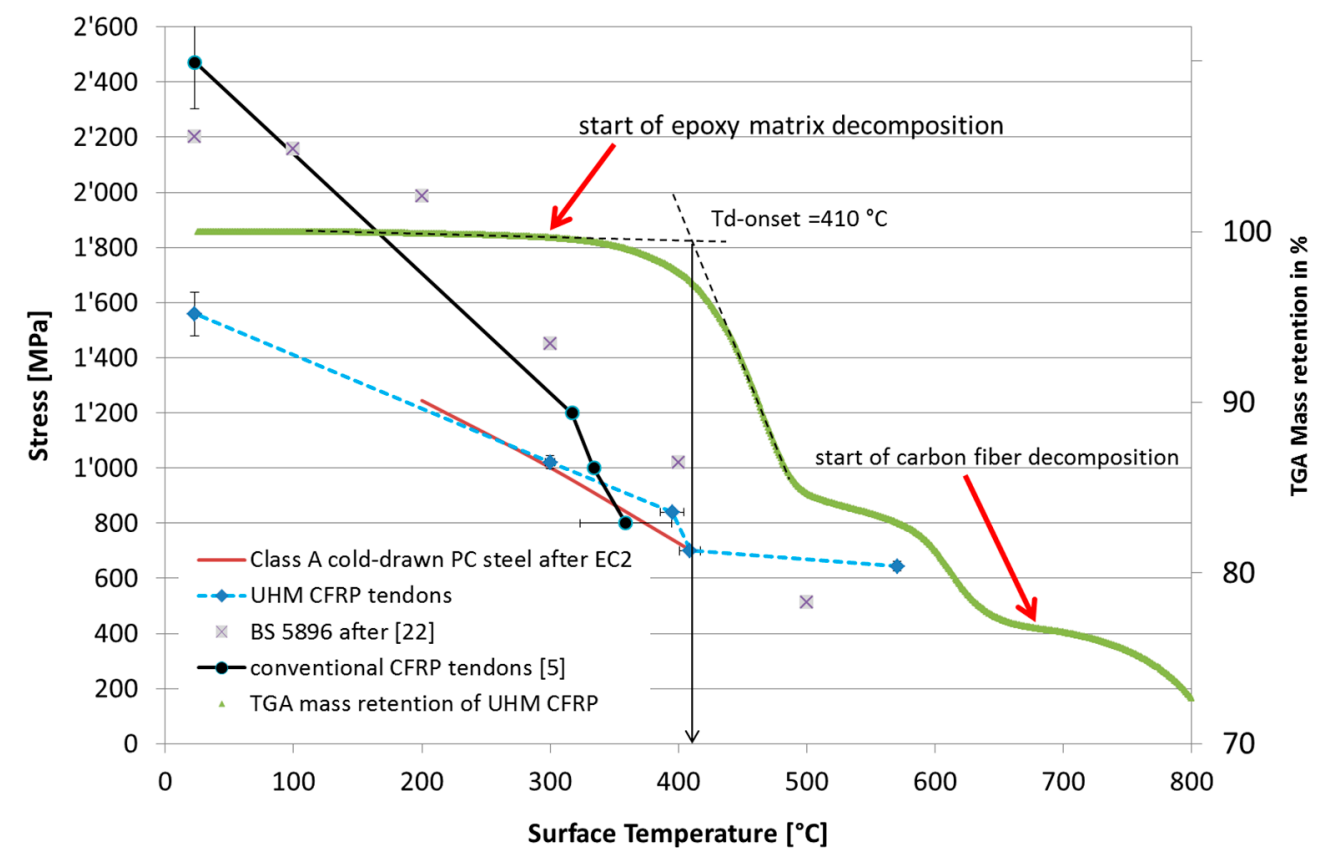

Figure 10. High-temperature tensile strength test results for novel UHM CFRP reinforcing tendons, compared against conventional CFRP tendons [6], BS 5896 steel prestressing wires [24], and guidance from Eurocode 1992-1-2 [25]; also including TGA mass loss curve for the novel UHM CFRP.

The first observation arising from Figure 10 is that typical steel prestressing wires also suffer considerable reductions in tensile strength at elevated temperatures. The figure also confirms the expectation that the Eurocode 1992-1-2 [25] tensile strength reduction recommendations are somewhat conservative (by approximately 60 to $100^{\circ} \mathrm{C}$ based on the limited results presented herein) with respect to the testing methods and modern steel prestressing materials used, for example, in [24]. This was previously verified by others [6].

Figure 10 shows that both UHM and conventional CFRP tendons [6] also experience considerable reductions in tensile strength under exposure to elevated temperatures. On average, the PAN-based normal modulus CFRP tendons described in $[1,6]$ are more sensitive to elevated temperature than a BS 5896 steel prestressing wire [24]; for example experiencing failure at a temperature about $70{ }^{\circ} \mathrm{C}$ lower than the steel at the a stress level of $1000 \mathrm{MPa}$. However, the main objective in the current study was the characterization of the elevated-temperature strength behaviour of the novel UHM CFRP tendons, which-If considered relative to their design tensile strength-Showed a better normalized retention of high temperature performance than the conventional PAN-based CFRP tendons. The design tensile strength of the normal modulus CFRP tendons is $2000 \mathrm{MPa}$ [1], while that of the new UHM 
tendons is only $1400 \mathrm{MPa}$. The novel UHM CFRP tendons show a failure temperature of $409{ }^{\circ} \mathrm{C}$ at a sustained stress level of $50 \%$ of their design tensile strength (700 $\mathrm{MPa})$, while the conventional CFRP tendons fail at an average temperature of $334{ }^{\circ} \mathrm{C}$ when loaded at $50 \%$ of their design tensile strength (i.e., $1000 \mathrm{MPa}$ ) [6]. For a sustained stress level of $1000 \mathrm{MPa}$, both tendon types fail in the same temperature range between 300 and $334{ }^{\circ} \mathrm{C}$.

Considering the shallower gradient of the loss of tensile strength of the novel UHM tendons with temperature, at $300{ }^{\circ} \mathrm{C}$ the average tensile strength of the tendons is $1021 \mathrm{MPa}(73 \%$ of their design DTS). At $570{ }^{\circ} \mathrm{C}$, the epoxy matrix of the tendons is almost fully decomposed, and therefore incapable of transferring shear stresses [15] amongst the individual carbon fibres (see the TGA curve in Figure 10). However, the average remaining tensile strength of the novel tendons is $644 \mathrm{MPa}$, which corresponds to $46 \%$ of DTS.

It is noteworthy that the maximum surface temperature of a CFRP tendon in an intact prestressed concrete slab of $75 \mathrm{~mm}$ total thickness, and subjected to an ISO 834 fire from one side, can be expected to reach between 450 and $475^{\circ} \mathrm{C}$ after $90 \mathrm{~min}$ [8]. For this type of fully prestressed slab [1] CFRP tendon prestress is typically $40 \%$ of the tendon design DTS (i.e., $560 \mathrm{MPa}$ for the UHM tendons in the current study). This is less than the tendons' remaining tensile strength at $570{ }^{\circ} \mathrm{C}(644 \mathrm{MPa}, \mathrm{Stdv} .18 \mathrm{MPa})$. Thus, this suggests that - at least with respect to the high temperature tensile strength performance-there is the potential to use the novel UHM CFRP tendons in CFRP pre-tensioned concrete elements for building applications [1,6] with up to $90 \mathrm{~min}$ of fire resistance.

The other important 'fire-performance' related issue that cannot be overlooked in this context is the understanding of the bond behaviour at high temperatures between the novel sand-coated UHM tendons and the concrete. For such prestressed concrete elements, CFRP anchorage regions with a limited temperature increase are essential. Combined experimental and numerical studies on these issues are being undertaken via a collaborative project between The University of Edinburgh and Empa.

It is widely considered that the upper temperature limit for CFRP used in civil engineering structural applications is given by the $T_{g}$ of the polymer resin matrix used in the CFRP composite profile fabrication [26]. For FRP composites used in infrastructure applications, $T_{g}$ is commonly measured in DMTA experiments and determined using a $T_{g}$-onset definition. This definition is shown in Figure 9, where the retained storage modulus $E^{\prime}(T)$ of the specimen is plotted versus the temperature for the CFRP tendons used in the current study. The $T_{g}$-onset value for the CFRP tendons was 115 to $117^{\circ} \mathrm{C}$ (Table 3). For comparison, the $T_{g}$ value for the novel UHM tendons was also determined with a $\tan \delta$ peak-definition (also shown in Figure 9), which gave-As anticipated in [27]—Somewhat higher values of $139-142{ }^{\circ} \mathrm{C}$ (Table 3 ). While it is clear that the loss in matrix modulus (and strength) for temperatures over $T_{g}$-onset influences the decrease of the remaining tensile strength of the CFRP tendon with temperature, this reduction is limited to approximately $540 \mathrm{MPa}$ in the temperature range 115 to $300{ }^{\circ} \mathrm{C}$ (Figure 10). This suggests that a considerable portion of the short-term tensile strength of the novel UHM CFRP tendons can be used at temperatures well above $T_{g}$ of the tendons' epoxy matrix (if the anchorage zones of the tendons are not subjected to high temperatures). This is a potentially important finding when designing for fire resistance of a UHM CFRP reinforced or prestressed concrete structural element.

Thermogravimetric analysis in air was used to determine if the temperature of onset of resin decomposition (e.g., approximated with a tangent intersection as $T_{d}$-onset in Figure 10), could be used to provide an indication of the temperatures which might lead to a considerably reduced transient thermal tensile strength of the UHM CFRP tendons. The thermal degradation was correlated and is displayed as the normalized reduction of the specimen's mass [28] in Figure 10. It can be observed that the thermal degradation of the epoxy resin starts at approximately $300{ }^{\circ} \mathrm{C}$, and ends at approximately $680{ }^{\circ} \mathrm{C}$, while the oxidation of the carbon fibres begins at about $680{ }^{\circ} \mathrm{C}$ and continues until the test finishes at $900{ }^{\circ} \mathrm{C}$. The comparison of the estimated $T_{d}$-onset value of $410{ }^{\circ} \mathrm{C}$ versus the temperatures needed to cause tensile rupture suggests that $T_{d}$-onset does not provide a particular 
indication of a necessarily 'critical' temperature for the tendons when stressed to reasonable service levels. Interestingly, at temperatures higher than $T_{d}$-onset the reduction in transient thermal tensile strength is limited. This suggests that at such high temperatures the carbon fibre bundle (tendon) does not experience any significant stress transfer between the fibres via the decomposing epoxy matrix. The composite action is therefore lost and the 'dry' fibres maintain the tensile strength in the range of 640 to $700 \mathrm{MPa}$. Clearly, this only holds for the stress levels and testing procedures used in the current study, and additional research on a variety of CFRP materials and sustained stress levels is necessary for verification and corroboration.

\section{Summary and Conclusions}

A novel ultra-high modulus CFRP prestressing tendon made from coal tar pitch-based carbon fibres was characterized in terms of high-temperature tensile strength (up to $570{ }^{\circ} \mathrm{C}$ ) with a series of transient thermal and steady temperature tensile tests. Digital image correlation was used to capture the high-temperature strain development during thermal and mechanical loading. Complementary thermogravimetric (TGA) and differential mechanical thermal (DTMA) experiments were also performed on the tendons to elucidate their high temperature thermal and mechanical behaviour.

The high-temperature tensile strengths determined for the novel UHM CFRP tendons are considered to be outstanding when compared to the high temperature performance of FRP reinforcements for concrete structures or conventional steel prestressing wires. A literature review in [7] revealed that at temperatures between 250 and $400{ }^{\circ} \mathrm{C}$, most carbon/epoxy CFRP composites lose about half of their original tensile strength. The novel UHM CFRP tendons investigated in the present study have a design tensile strength (DTS) of $1400 \mathrm{MPa}$; their failure temperature at a prestress of $50 \%$ of the design tensile strength is $409^{\circ} \mathrm{C}$. Conventional PAN-based CFRP tendons investigated by the same authors [6] failed at an average temperature of only $334{ }^{\circ} \mathrm{C}$ when loaded to $50 \%$ of their design tensile strength. It is noteworthy that at $300{ }^{\circ} \mathrm{C}$ the average tensile strength of the novel UHM tendons studied was still $1021 \mathrm{MPa}$ (73\% of their design tensile strength). This shows that a considerable part of the short-term tensile strength of the novel UHM CFRP tendons can be used at temperatures well above the $T_{g}$ of the tendons' epoxy matrix $\left(115^{\circ} \mathrm{C}\right)$. At $570{ }^{\circ} \mathrm{C}$, the epoxy matrix of the tendons was almost fully decomposed and therefore incapable of transferring shear loads amongst the individual carbon fibres. This was confirmed using TGA experiments. However, the average remaining tensile strength of the novel tendons was $644 \mathrm{MPa}$, which corresponds to $46 \%$ of their design tensile strength. This relatively high remaining tensile strength at $570{ }^{\circ} \mathrm{C}$ shows that there is potential to use the novel UHM CFRP tendons in CFRP pre-tensioned concrete elements for building applications that fulfill the fire resistance criteria (e.g., for an ISO 834 design fire scenario) [1,6,8]. Additional research is needed to confirm this conclusion.

Acknowledgments: We are grateful to Michel Barbezat for performing the DMTA measurements and to Empa for financial support. The UK Royal Academy of Engineering is acknowledged for the support of Bisby and for granting a distinguished visiting fellowship to Terrasi and The University of Edinburgh. Ove Arup and Partners Limited are acknowledged for their ongoing support of Bisby. Cristian Maluk is acknowledged for his generous support in discussions on the fire performance of CFRP prestressed concrete elements.

Author Contributions: Giovanni Pietro Terrasi was responsible for the design and for performing the experiments and for their evaluation and interpretation. The production, anchorage and tensile testing of the CFRP specimens at ambient temperature were performed by Tobias D. Lämmlein. DIC measurements and analysis were undertaken by Emma R. E. McIntyre, who generously supported the main experiments. Luke A. Bisby and Giovanni Pietro Terrasi initiated the study, and with Pietro Lura they wrote the paper, regularly and critically reviewed and coordinated the project and performed the result analysis. Furthermore, they were very involved in the literature analysis.

Conflicts of Interest: The authors declare no conflict of interest. 


\section{References}

1. Terrasi, G.P. Prefabricated Thin-walled Structural Elements Made from High Performance Concrete Prestressed with CFRP Wires. J. Mater. Sci. Res. 2013, 2, 1-14. [CrossRef]

2. FRP Reinforced Concrete Association the European German Speaking Countries. Available online: http://www.carbon-composites.eu/de/netzwerk/abteilungen/cc-tudalit (accessed on 24 October 2016).

3. Hegger, J.; Goralski, C.; Kulas, C. A Pedestrian Bridge Made of Textile Reinforced Concrete. Beton Stahlbetonbau 2011, 106, 64-71. [CrossRef]

4. Produktinformationen zu Fassadenelementen aus Carbolith ${ }^{\circledR}$. Available online: https://www.sacac.ch/de/ angebot/fassadenelemente/carbolith-elemente (accessed on 24 October 2016).

5. Terrasi, G.P. Carbon Fiber Prestressed Spun Concrete Poles. Ph.D. Thesis, Eidgenössische Technische Hochschule (ETH), Zurich, Switzerland, 1998. (In German)

6. Maluk, C.; Bisby, L.; Terrasi, G.P.; Hugi, E.; Green, M. Bond Strength Degradation for CFRP and Steel Reinforcing Bars in Concrete at Elevated Temperature; American Concrete Institute Special Publication on Advances in Fire Design of Concrete Structures (ACI SP-297); American Concrete Institute: Farmington Hills, MI, USA, 2011; p. 36.

7. Bisby, L.A. Fire Behaviour of FRP Reinforced or Confined Concrete. Ph.D. Thesis, Department of Civil Engineering, Queen's University, Kingston, ON, Canada, 2003; p. 329.

8. Terrasi, G.P.; Bisby, L.; Barbezat, M.; Affolter, C.; Hugi, E. Fire Behaviour of Thin CFRP Pretensioned High Strength Concrete Slabs. J. Compos. Constr. 2012, 16, 381-394. [CrossRef]

9. Lura, P.; Terrasi, G.P. Reduction of fire spalling in high-performance concrete by means of superabsorbent polymers and polypropylene fibers-Small scale fire tests of carbon fiber reinforced plastic-prestressed self-compacting concrete. Cem. Concr. Compos. 2014, 49, 36-42. [CrossRef]

10. Pitch-Based Carbon Fiber (CF) <<DIALEAD >>. Available online: https://www.mrc.co.jp/dialead/english/ dialead.html (accessed on 24 October 2016).

11. Terrasi, G.P.; Affolter, C.; Barbezat, M. Numerical Optimization of a Compact and Reusable Pre-tensioning Anchorage System for CFRP Tendons. J. Compos. Constr. 2010, 15, 126-135. [CrossRef]

12. Tape Laying. Available online: http://www.automateddynamics.com/automation-equipment/tape-laying (accessed on 24 October 2016).

13. Material Data Sheet. Available online: http://www.huntsman.com/advanced_materials/Media\%20Library/ global/files/EUR (accessed on 24 October 2016).

14. EN2561 Standard. Carbon Fibre Reinforced Plastics; Unidirectional Laminates. Tensile Test Parallel to the Fiber Direction; Beuth Verlag GmbH: Berlin, Germany, 1995.

15. Schürmann, H. Konstruieren Mit Faser-Kunststoff-Verbunden; Springer: Berlin Heidelberg, Germany, 2007.

16. UTS Carbon Fiber Properties. Available online: http://tenaxtoho.de/deutsch/main/produkte/ Aenderungen\%20Marz\%202007/Produktprogramm_UTS.pdf (accessed on 20 December 2016).

17. Datasheet Rutapox 4434 Resin. Available online: http://www.g-angeloni.com/elenco-prodotti/resins/epr04434-eph-04434/ (accessed on 20 December 2016).

18. Spannstahl Draht. Available online: http://www.nedri.nl/de/produkte/spannstahl-draht.html (accessed on 24 October 2016).

19. Werkstoffdatenblatt ETG 88/100. Available online: http://www.frebel-obstfeld.de/download/18 (accessed on 24 October 2016).

20. Bisby, L.A.; Take, W.A. Strain Localizations in FRP Confined Concrete: New Insights. ICE Struct. Build. 2009, 162, 301-309. [CrossRef]

21. Standard ASTM D4065. Standard Practice for Plastics: Dynamic Mechanical Properties: Determination and Report of Procedures; ASTM International: West Conshohocken, PA, USA, 2012.

22. Cleveland, W.S. Robust locally weighted regression and smoothing scatterplots. J. Am. Stat. Assoc. 1979, 74, 829-836. [CrossRef]

23. Fukunaga, A.; Ueda, S.; Nagumo, M. Air-oxidation and anodization of pitch-based carbon fibers. Carbon 1999, 37, 1081-1085. [CrossRef]

24. Gales, J.; Bisby, L.; Stratford, T. High Temperature Creep Deformation and Failure Behavior of Prestressing Steel. In Proceedings of the Seventh International Conference on Structures in Fire (SiF 2012), Zurich, Switzerland, 6-8 June 2012; pp. 659-668. 
25. Eurocode 2. Design of Concrete Structures_Part 1-2: General Rules—Structural Fire Design (BS EN 1992-1-2); European Committee for Standardization: Brussels, Belgium, 2004; p. 97.

26. ACI Committee 440. Guide for the Design and Construction of Externally Bonded FRP Systems for Strengthening Concrete Structures (ACI 440.2R-08); American Concrete Institute: Farmington Hills, MI, USA, 2008; p. 76.

27. Akay, M. Aspects of dynamic mechanical analysis in polymeric composites. Compos. Sci. Technol. 1993, 47, 419-423. [CrossRef]

28. ASTM International. Standard Test Method for Loss-on-Drying by Thermogravimetry (ASTM E1868-09); American Society for Testing and Materials: West Conshohocken, PA, USA, 2009; p. 4.

(C) 2016 by the authors; licensee MDPI, Basel, Switzerland. This article is an open access article distributed under the terms and conditions of the Creative Commons Attribution (CC-BY) license (http:/ / creativecommons.org/licenses/by/4.0/). 